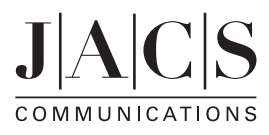

Published on Web 01/11/2005

\title{
Titania-Supported PdAu Bimetallic Catalysts Prepared from Dendrimer-Encapsulated Nanoparticle Precursors
}

\author{
Robert W. J. Scott, Chinta Sivadinarayana, Orla M. Wilson, Zhen Yan, D. Wayne Goodman, and \\ Richard M. Crooks*
}

Department of Chemistry, Texas A\&M University, P. O. Box 30012, College Station, Texas 77842-3012

Received September 13, 2004; E-mail: crooks@tamu.edu

In this communication, we report the synthesis and characterization of $\mathrm{TiO}_{2}$-supported $\mathrm{PdAu}$ bimetallic nanoparticle catalysts prepared using dendrimer-encapsulated nanoparticles (DENs). ${ }^{1}$ The key result is that the compositional fidelity of the original bimetallic DENs, and to some extent their size, is retained in the supported catalyst after removal of the dendrimer template by calcination at $500{ }^{\circ} \mathrm{C}$. Additionally, the gas-phase catalytic activity for $\mathrm{CO}$ oxidation is higher for the bimetallic catalysts than that for the corresponding Pd-only and Au-only monometallics. ${ }^{2,3}$

It has previously been shown that $1-3-\mathrm{nm}$ diameter alloy and core-shell bimetallic PdPt, ${ }^{4,5} \mathrm{PdAu},{ }^{6} \mathrm{PdRh}^{7}{ }^{7}$ and $\mathrm{AuAg}^{8}$ nanoparticles can be synthesized within dendrimer templates. ${ }^{1}$ The resulting materials are characterized by a high degree of uniformity in size, structure, and elemental composition, and in some cases they have enhanced solution-phase catalytic activities compared to the analogous monometallic materials. ${ }^{4-7}$ There are also a few examples of dendrimer/nanoparticle composites of various sorts being used to prepare supported $\mathrm{Pt},{ }^{9} \mathrm{Pd},{ }^{10} \mathrm{Au},{ }^{10} \mathrm{CuO},{ }^{11}$ and $\mathrm{Fe}_{2} \mathrm{O}_{3}$ nanoparticles. ${ }^{12}$ In some cases, these were shown to be catalytically active..$^{9,12}$ To the best of our knowledge, however, there is only one very recent example of a heterogeneous catalyst prepared from a bimetallic DEN precursor. ${ }^{13}$ The DEN approach to bimetallic nanoparticles is potentially simpler than many alternative methods. For example, organometallic cluster precursors containing two different metals have been used to prepare supported bimetallic catalysts, but continuous variation of the elemental composition of the resulting particles requires large precursor libraries. ${ }^{14-16}$ Most other methods for preparing supported bimetallic nanoparticles in the $<5-\mathrm{nm}$ size range lead to phase segregation of the two metals and thus poor control over the composition of individual particles, ${ }^{17}$ although limited success has been achieved using surfactant-stabilized nanoparticles. ${ }^{18}$

We prepared DENs consisting of PdAu alloys within fourthgeneration, amine-terminated poly(amidoamine) (PAMAM) dendrimers $\left(\mathrm{G} 4-\mathrm{NH}_{2}\left(\mathrm{Pd}_{n} \mathrm{Au}_{55-n}\right)\right)$ by co-complexation of the two corresponding metal salts followed by chemical reduction of the dendrimer/metal-ion composite. ${ }^{6}$ The synthesis was carried out in a $99 \%$ methanol solution using a procedure we previously reported for preparing DENs within amine-terminated dendrimers. ${ }^{10}$ For example, $\mathrm{G} 4-\mathrm{NH}_{2}\left(\mathrm{Pd}_{27.5} \mathrm{Au}_{27.5}\right)$ was synthesized as follows: 0.0924 g of a 14.2 wt \% solution of $\mathrm{G} 4-\mathrm{NH}_{2}$ in $\mathrm{MeOH}$ and $20 \mu \mathrm{L}$ of 0.3 $\mathrm{M} \mathrm{HCl}$ were added to $1 \mathrm{~L}$ of $99 \% \mathrm{MeOH}$, followed by $255 \mu \mathrm{L}$ of a $0.10 \mathrm{M} \mathrm{K}_{2} \mathrm{PdCl}_{4}$ solution. The $\mathrm{HCl}$ was added to prevent crosslinking of the $\mathrm{G} 4-\mathrm{NH}_{2}$ dendrimer by $\mathrm{Pd}^{2+}\left(\mathrm{Pd}^{2+}\right.$ is used to designate $\mathrm{PdCl}_{4}{ }^{2-}$ and all its hydrolysis products). ${ }^{19}$ After being stirred for $10 \mathrm{~min}, 255 \mu \mathrm{L}$ of a $0.10 \mathrm{M} \mathrm{HAuCl}_{4}$ solution was added. After being stirred for an additional $2 \mathrm{~min}, 1 \mathrm{~mL}$ of a $1.0 \mathrm{M} \mathrm{NaBH}_{4}$ solution was added $(20 \times$ molar excess $)$. The solution was stirred for $3 \mathrm{~h}$ under $\mathrm{N}_{2}$ and used for the sol-gel synthesis described next. Transmission electron microscopy (TEM) indicated that the G4-
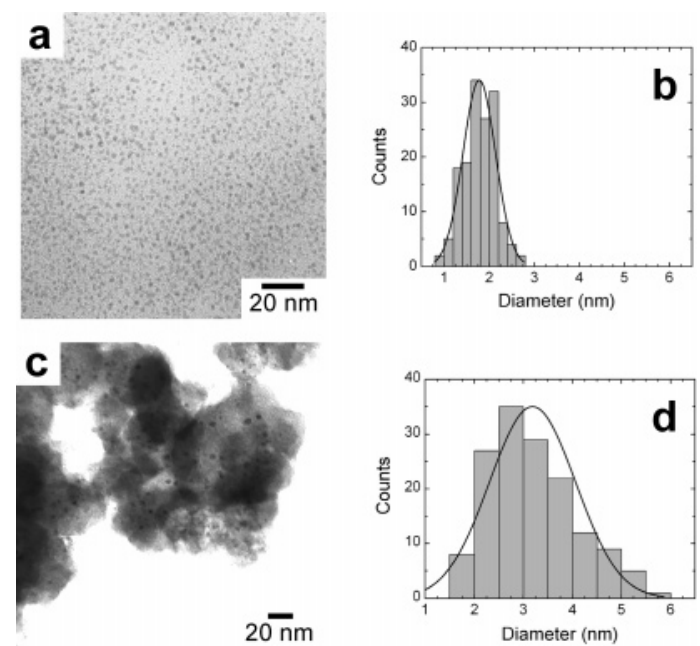

Figure 1. Bright-field TEM images and particle-size distributions for G4$\mathrm{NH}_{2}\left(\mathrm{Pd}_{27.5} \mathrm{Au}_{27.5}\right)$ DENs prepared by co-complexation of the corresponding metal salts followed by reduction. (a), (b) As synthesized. (c), (d) After incorporation into the titania matrix and subsequent calcination at $500{ }^{\circ} \mathrm{C}$ under $\mathrm{O}_{2}$ and $\mathrm{H}_{2}$.

$\mathrm{NH}_{2}\left(\mathrm{Pd}_{27.5} \mathrm{Au}_{27.5}\right)$ DENs had an average particle size of $1.8 \pm 0.4$ $\mathrm{nm}$ (Figure 1), which is in accord with previous results for closely related materials. ${ }^{6,10} \mathrm{G} 4-\mathrm{NH}_{2}\left(\mathrm{Pd}_{55}\right)$ and $\mathrm{G} 4-\mathrm{NH}_{2}\left(\mathrm{Au}_{55}\right)$ were prepared in a similar manner, and they also had properties similar to those reported previously. ${ }^{10}$

$\mathrm{PdAu}, \mathrm{Pd}$, and $\mathrm{Au}$ DEN solutions were used to prepare $\mathrm{TiO}_{2}$ powders containing $1 \mathrm{wt} \%$ of the metals. The $\mathrm{PdAu} / \mathrm{TiO}_{2}$ composite was prepared as follows. To a solution of $\mathrm{G} 4-\mathrm{NH}_{2}\left(\mathrm{Pd}_{27.5} \mathrm{Au}_{27.5}\right)$, $0.3 \mathrm{M} \mathrm{HCl}$ was added to neutralize excess $\mathrm{NaBH}_{4}$. After being stirred for $2 \mathrm{~h}, 3.52 \mathrm{~g}$ of $\mathrm{Ti}\left(\mathrm{O}^{\mathrm{i} P r}\right)_{4}$, dissolved in $5 \mathrm{~mL}$ of $\mathrm{MeOH}$ dried over molecular sieves, was added dropwise to the solution. The solution became turbid over a period of $30-60 \mathrm{~s}$ as the alkoxide precursor hydrolyzed. After $5 \mathrm{~min}, 100 \mathrm{~mL}$ of $\mathrm{H}_{2} \mathrm{O}$ was added. The resulting solution was left for $24 \mathrm{~h}$, and then the precipitate was filtered and dried at $100{ }^{\circ} \mathrm{C}$ for $24 \mathrm{~h}$. The final product was recovered in yields of $40-60 \%$ (not all of the $\mathrm{TiO}_{2}$ precursor was incorporated into the matrix). The powder was then sequentially calcined at $500{ }^{\circ} \mathrm{C}$ in flowing $\mathrm{O}_{2}$ and then $\mathrm{H}_{2}$ for $1 \mathrm{~h}$ each. ${ }^{20}$

Thermogravimetric and elemental analysis of the $\mathrm{G} 4-\mathrm{NH}_{2}\left(\mathrm{Pd}_{27.5^{-}}\right.$ $\mathrm{Au}_{27.5} / \mathrm{TiO}_{2}$ composite indicated that the dendrimer was removed during calcination (Supporting Information). ${ }^{10}$ The average particle size increased after calcination from $1.8 \pm 0.4 \mathrm{~nm}$ to $3.2 \pm 0.9 \mathrm{~nm}$ (Figure 1). This increase is consistent with the harsh pyrolysis conditions required to completely remove the dendrimer, ${ }^{21}$ and it is comparable to the increase in size observed for monometallic $\mathrm{Pd}$ and $\mathrm{Au}$ nanoparticles calcined under the same conditions (3.0 $\pm 0.6 \mathrm{~nm}$ and $2.7 \pm 0.6 \mathrm{~nm}$, respectively). ${ }^{10}$ Large-area energydispersive spectroscopy (EDS) of the calcined catalyst indicated an average composition of $48 \pm 3 \% \mathrm{Pd}$ and $52 \pm 3 \% \mathrm{Au}$, which 


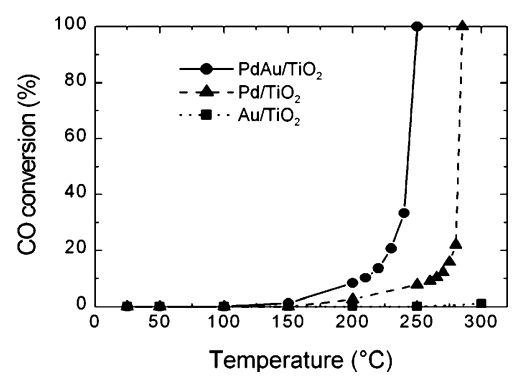

Figure 2. Percentage $\mathrm{CO}$ oxidation as a function of temperature for $\mathrm{PdAu}$, Pd-only, and Au-only catalysts supported on $\mathrm{TiO}_{2}$. The catalysts were prepared using G4-NH $\mathrm{N}_{2}\left(\mathrm{Pd}_{27.5} \mathrm{Au}_{27.5}\right), \mathrm{G} 4-\mathrm{NH}_{2}\left(\mathrm{Pd}_{55}\right)$, and $\mathrm{G} 4-\mathrm{NH}_{2}\left(\mathrm{Au}_{55}\right)$ DENs, respectively. Catalytic reactions were carried out using a 2:1 ratio of $\mathrm{O}_{2} / \mathrm{CO}$ and a gas hourly space velocity of $20000 \mathrm{~cm}^{3} \cdot \mathrm{g}^{-1} \cdot \mathrm{h}^{-1}$.

is in agreement with the molar percentages of $\mathrm{PdCl}_{4}{ }^{2-}$ and $\mathrm{AuCl}_{4}{ }^{-}$ used in the original synthesis mixture (50\% each). Importantly, the composition of the individual nanoparticles in the catalyst can be controlled by varying the percentage of the two metal salts complexed within the dendrimer at the beginning of the synthesis. For example, quantitative, standardless EDS analysis of 13 particles prepared from a $\mathrm{G} 4-\mathrm{NH}_{2}\left(\mathrm{Pd}_{14} \mathrm{Au}_{41}\right) / \mathrm{TiO}_{2}$ precursor (Supporting Information) resulted in average Pd and Au compositions of $19 \pm$ $2 \%$ and $81 \pm 2 \%$, respectively. These values are comparable to the molar percentages of $\mathrm{PdCl}_{4}{ }^{2-}$ and $\mathrm{AuCl}_{4}{ }^{-}$originally complexed within the dendrimers ( 25 and $75 \%$, respectively). The low standard deviations of the EDS measurements clearly indicate a high degree of compositional uniformity. This is a significant advantage of preparing the nanoparticles prior to immobilization on the support. ${ }^{17}$

As alluded to earlier, the dendrimer interior is a template for the encapsulated nanoparticles in that it controls their size and elemental composition. In addition, however, the exterior of the dendrimer templates the porosity of the titania support. ${ }^{10,11}$ This is important, because effective heterogeneous catalysts must have high surface areas and a significant degree of meso- and macroporosity. ${ }^{22}$ The surface area of the $\mathrm{NH}_{2}\left(\mathrm{Pd}_{27.5} \mathrm{Au}_{27.5}\right) / \mathrm{TiO}_{2}$ composite was found to increase from $35.7 \mathrm{~m}^{2} / \mathrm{g}$ to $51.9 \mathrm{~m}^{2} / \mathrm{g}$ following calcination, and the BJH pore diameter of the calcined material reveals a welldefined peak centered at $3.5 \mathrm{~nm}$ (Supporting Information). This result indicates that the imprint of the $\mathrm{G} 4-\mathrm{NH}_{2}$ dendrimer, which has a solution-phase diameter of $\sim 4.5 \mathrm{~nm},{ }^{1}$ remains in the titania following calcination.

Figure 2 compares the catalytic $\mathrm{CO}$ oxidation activity for $\mathrm{TiO}_{2}-$ supported catalysts prepared with G4-NH $\mathrm{NH}_{2}\left(\mathrm{Pd}_{27.5} \mathrm{Au}_{27.5}\right), \mathrm{G} 4-\mathrm{NH}_{2-}$ $\left(\mathrm{Pd}_{55}\right)$, and $\mathrm{G} 4-\mathrm{NH}_{2}\left(\mathrm{Au}_{55}\right)$. The temperature for onset of catalytic activity ( $1 \% \mathrm{CO}$ conversion) for the PdAu catalyst is $150^{\circ} \mathrm{C}$, while the $\mathrm{Pd}$ and $\mathrm{Au}$ catalysts are inactive at this temperature. Complete (100\%) $\mathrm{CO}$ conversion occurs at $250^{\circ} \mathrm{C}$ and $285^{\circ} \mathrm{C}$ for PdAu and Pd DENs, respectively, which indicates a synergetic electronic ligand effect. $^{2,3}$ Interestingly, the Au-only supported catalysts exhibited no activity toward $\mathrm{CO}$ oxidation at temperatures $<300$ ${ }^{\circ} \mathrm{C} .{ }^{23}$ Lifetime measurements of the PdAu catalysts indicated that $100 \%$ CO oxidation activity was retained for $24 \mathrm{~h}$, but after this time there was a loss in activity of $60-80 \%$ over a period of about two days, possibly due to coking.

To summarize, we have described an approach for the synthesis of well-defined, bimetallic PdAu nanoparticles supported on $\mathrm{TiO}_{2}$.
Single-particle EDS analysis of individual nanoparticles confirms that they are bimetallic and have approximately the same atomic composition as the ratio of the metal salts used in the original reaction mixture. The supported bimetallic PdAu nanoparticles prepared by this method showed a synergetic catalytic effect toward $\mathrm{CO}$ oxidation compared to supported Pd-only and Au-only catalysts. These results are important, because they provide a general and simple route for preparing supported bimetallic catalysts that are nearly monodisperse in both size and composition.

Acknowledgment. We gratefully acknowledge the Robert A. Welch Foundation and the U.S. Department of Energy, DOE-BES Catalysis Science Grant No. DE-FG02-03ER15471 for financial support of this work. Single-particle EDS measurements were performed with the assistance of Dr. Edward A. Kenik at the Oak Ridge National Laboratory SHaRE User Center, which is supported by the Division of Materials Sciences and Engineering, DOE, under Contract DE-AC05-00OR22725 with UT-Battelle, LLC. We also thank Mr. Shane Carr and Prof. Daniel F. Shantz of the Department of Chemical Engineering at Texas A\&M University for assistance with gas adsorption measurements.

Supporting Information Available: HAADF TEM image of G4$\mathrm{NH}_{2}\left(\mathrm{Pd}_{14} \mathrm{Au}_{41}\right)$ DENs after calcination, thermogravimetric analysis, elemental analysis, gas adsorption isotherms, and BJH pore-size distributions for $\mathrm{TiO}_{2}$-supported $\mathrm{PdAu}$ catalysts. This material is available free of charge via the Internet at http://pubs.acs.org.

\section{References}

(1) Scott, R. W. J.; Wilson, O. M.; Crooks, R. M. J. Phys. Chem. B. 2005 109, 692-704

(2) Toshima, N.; Yonezawa, T. New J. Chem. 1998, 22, 1179-1201.

(3) Sinfelt, J. H. Bimetallic Catalysts: Discoveries, Concepts and Applications Wiley: New York, 1983.

(4) Scott, R. W. J.; Datye, A. K.; Crooks, R. M. J. Am. Chem. Soc. 2003 125, 3708-3709.

(5) Chung, Y. M.; Rhee, H. K. Catal. Lett. 2003, 85, 159-164.

(6) Scott, R. W. J.; Wilson, O. M.; Oh, S.-K.; Kenik, E. A.; Crooks, R. M J. Am. Chem. Soc. 2004, 126, 15583-15591.

(7) Chung, Y. M.; Rhee, H. K. J. Mol. Catal. A: Chem. 2003, 206, $291-$ 298.

(8) Wilson, O. M.; Scott, R. W. J.; Garcia-Martinez, J. C.; Crooks, R. M. J. Am. Chem. Soc. 2005, 127, 1015-1024

(9) Lang, H.; May, R. A.; Iversen, B. L.; Chandler, B. D. J. Am. Chem. Soc 2003, 125, 14832-14836.

(10) Scott, R. W. J.; Wilson, O. M.; Crooks, R. M. Chem. Mater. 2004, 16, $5682-5688$

(11) Velarde-Ortiz, R.; Larsen, G. Chem. Mater. 2002, 14, 858-866.

(12) Choi, H. C.; Kim, W.; Wang, D.; Dai, H. J. Phys. Chem. B 2002, 106, $12361-12365$.

(13) Lang, H.; Maldonado, S.; Stevenson, K. J.; Chandler, B. D. J. Am. Chem Soc. 2004, 126, 12949-12956.

(14) Nashner, M. S.; Frenkel, A. I.; Adler, D. L.; Shapley, J. R.; Nuzzo, R. G J. Am. Chem. Soc. 1997, 119, 7760-7771.

(15) Raja, R.; Sankar, G.; Hermans, S.; Shephard, D. S.; Bromley, S.; Thomas, J. M.; Johnson, B. F. G. Chem. Commun. 1999, 1571-1572.

(16) Alexeev, O. S.; Gates, B. C. Ind. Eng. Chem. Res. 2003, 42, 1571-1587.

(17) Choudhary, T. V.; Sivadinarayana, C.; Datye, A. K.; Kumar, D.; Goodman, D. W. Catal. Lett. 2003, 86, 1-8.

(18) Bönnemann, H.; Braun, G.; Brijoux, W.; Brinkmann, R.; Tilling, A. S ; Seevogel, K.; Siepen, K. Organomet. Chem. 1996, 520, 143-162.

(19) Scott, R. W. J.; Ye, H.; Henriquez, R. R.; Crooks, R. M. Chem. Mater. 2003, 15, 3873-3878.

(20) Choudhary, T. V.; Sivadinarayana, C.; Chusuei, C. C.; Datye, A. K.; Fackler, J. P.; Goodman, D. W. J. Catal. 2002, 207, 247-255.

(21) Buffat, P.; Borel, J.-P. Phys. Rev. A 1976, 13, 2287-2298.

(22) Pietron, J. J.; Stroud, R. M.; Rolison, D. R. Nano Lett. 2002, 2, 545549

(23) Valden, M.; Lai, X.; Goodman, D. W. Science 1998, 281, 1647-1650. JA044446H 